Egbedoyin, F. S

The Role of Leadership in Tacit Knowledge Transfer in the Nigerian Oil and Gas Industry. niyiegbedoyin@yahoo.com

Folfun International Inc., Canton, Michigan, USA

This article is covered and protected by copyright law and all rights reserved exclusively by the Centre for Petroleum, Pollution Control and Corrosion Studies (CEFPACS) Consulting Limited.

Please note that the opinion expressed in this article remain that of the author(s).

Electronic copies available to authorised users.

The link to this publication is https://ajoeer.org.ng/otn/ajoeer/qtr-1/2021/07.pdf 
The Role of Leadership in Tacit Knowledge Transfer in the Nigerian Oil and Gas Industry.

\author{
${ }^{1}$ Funminiyi S. Egbedoyin and ${ }^{2}$ Edward P. Agbai \\ ${ }^{1}$ Folfun International Inc., Canton, Michigan, USA \\ niyiegbedoyin@yahoo.com
}

\author{
${ }^{2}$ Smart Alliance Consulting Services Ltd, \\ Saskatoon, Saskatchewan, Canada.
}

Received: October 19, 2020; Received in reversed form: November 25, 2020; Accepted:

November 27, 2020.

\begin{abstract}
The oil and gas industries are knowledge driven industry. The technology deployed in deep water exploration and production involve knowledge-intensive process by highly technical personnel. The problem was that the leadership of the oil and gas industries have not necessitated early recovery of tacit knowledge transfer from experts to employees managing the plant operations. The purpose of this qualitative multiple case study was to gain an understanding of how oil and gas industry leaders in Nigeria facilitate the transfer of tacit knowledge from experts to employees managing the plant after exploration activities. The conceptual framework was the socialization, externalization, combination, and internalization model developed by Nonaka and Takeuchi and Burns' transformational leadership theory. A qualitative multiple case study design was used by adopting multiple sources of information including semi-structured interviews, field notes, and review of organizational documents. The unit of analysis was leaders in an oil and gas services organization. The data analysis processes involved coding of the data, categorizing the coded data, and subsequently generating themes in line with the research question using NVivo Version 12 software. Findings indicated that leaders facilitated the transfer of tacit knowledge through the creation of a safe working environment and demonstration of care for the employees. The opportunity to facilitate the transfer of tacit knowledge from expert to employees managing
\end{abstract}


operations after exploration enhance the organization's stability and promotes healthy communities.

Keywords-Knowledge-Transfer, Leadership Style, Oil and Gas Industry

\section{0: INTRODUCTION}

The oil and gas industries have seen a declined in the price of the products due the COVID-19 pandemic leading to reduction in drilling operations and general jobs losses in the industry [10]. The oil and gas industries are knowledge driven industry. The technology deployed in deep water exploration and production involve knowledge-intensive process by highly technical personnel of services firms [21]. The industry leverages on the expertise of their skilled workforces for operational continuity and competitive advantage [15;26]. Tacit knowledge has unique peculiarities in a knowledge-based organization. The technical and professional skills of industry operators from the employees to contractor and consultants are critical to the operational continuity in the industry [28: 38]. It has become imperative for leadership in servicing organizations to shift attention from physical to intellectual assets [30].

Industry experts has long recognized the importance of knowledge transfer and the corresponding support of leadership in the management of such knowledge. Knowledge management $(\mathrm{KM})$ is a vital and requisite tool to gaining a competitive advantage in servicing companies [19]. The ability of the drilling and servicing companies to transfer tacit knowledge after drilling and workovers to the operating companies may enable the operating companies to preserve critical knowledge and promote operational continuity [15]. The key resource personnel needed for the sustainability of the oil and gas companies are the knowledge of the employees and contractors who worked for services organizations or are currently working for the oil and gas companies [30]. Loss of these key personnel due to change of job and retirement may be inevitable, there could be a transfer of knowledge to other employees through knowledge sharing [50]. The sudden exit and attrition of experienced employees greatly impacts on the future workforce, where the practiceof knowledge transfer strategies is non-existent [25: 41].

Tacit knowledge transfer has a long-term impact on the company growth [37]. The lack of quality in knowledge transfer practice might limit the usefulness of the captured tacit knowledge to enhance organizations' bottom line [28]. Only few organizations within the oil and gas industries have a formal strategy for knowledge retention of experienced employees and developed sustainable methods of eliminating loss in the process of knowledge transfer [42:14]. The 
understanding of how leaders facilitate the transfer of tacit knowledge withinthe organizations like the oil and gas companies is significant [22: 30]. This research was conducted to gain an understanding of how leaders in services companies in the oil and gas industries facilitate the transfer of tacit knowledge among employees. This study provides an opportunity on how leveraging on the transfer of tacit knowledge from experienced employees to new employees at an oil and gas company may enhance the growth of the organization.

\section{2: Problem Statement}

The projected number of aging or experienced workers exiting the oil and gas industry in Nigeria between 2015 and 2025 will create a labor scarcity that will affect the manpower need of the industry [42]. The knowledge gap created is due to the labor scarcity created by the exit of experienced personnel. A survey administered by the Technology Services Industry Association in $\mathrm{KM}$ across industries showed that $43 \%$ of the 300 respondents thought that there are unqualified employees because of inadequate knowledge [40].

The general management problem is that despite the efforts in capturing tacit knowledge, leaders of organizations have not fully realized the benefit of tacit knowledge [24: 28:36]. The specific problem is that the efforts of the leaders of organizations in the oil and gas industries in eliminating loss in the transfer of tacit knowledge among employees have not been realized [17:49].

\section{3: Purpose of the Study}

The purpose of this qualitative exploratory multiple case study was to gain an understanding of how leaders in an oil and gas companies in Nigeria facilitate the transfer of tacit knowledge among employees. The goal of qualitative research is to gain an understanding of a situation, individuals, or group of people. The choice of a case study is to enables the researcher to gain indepth understanding of the phenomenon of interest[1:5].

\section{4: Research Questions}

The overarching research question was: How do leaders in the oil and gas industries facilitate the transfer of tacit knowledge among employees? 


\section{5: Conceptual Framework}

The conceptual framework for this study was based on (a) the socialization, externalization, combination, and internalization (SECI) model developed by Nonaka and Takeuchi (1995), and (b) transformational leadership theory [9]. Knowledge creation is a dynamic process of spiral interaction of explicit and tacit knowledge and involves the transfer of tacit and explicit knowledge among individuals and groups of individuals within and outside organizations [35]. In this dynamic process of knowledge creation, there is a continuous interaction among varied levels of employees. Research has shown that the leadership role is critical to the outcome of the interaction [47].

\section{0: LITERATURE REVIEW}

\section{1: Leadership in Oil and Gas Industry}

A leader is someone that guides others and leadership is the ability to guide and direct others [45]. In today's changing business world, the leader should be open to change and should influence the employees to change and be involved in the change process [45]. A leader with confidence would believe in followers, consequently, employees will believe and demonstrate high level of motivation in following the leader [6]. The goal of leaders is to empower employees in optimizing their potentials through the concern for others, openness, and support [6]. These leadership qualities make the team feel welcome and wanting to work and follow the leader. The probability of being committed to working for lack of trust in the leader is one out of twelve [46].

The leader acts as the change agent and must communicate what and why the change to protect the integrity of the information [44]. Leaders should have visions of a future with corresponding action plans to accomplish them [44]. The action plans should also include how to motivate employees to relate to the vision [44]. The leader should be apparent in their message and develop an effective communication plan towards accomplishing the goal. For communication to be effective, the message must be repeated several times to achieve good understanding and for employees to buy-in [6]. A leader, being a role model promotes and sustains organizational goals. A leader drives the followers' actions throughout the organization [6]. The leader's role affects everything from attitudes to work and the management of knowledge transfer processes [44]. Moreover, as a role model, the leader's words should match the actions [45]. Tacit knowledge is crucial for an organization's competitive advantage [17], and leaders should be mindful of their roles in the process of managing the transfer of valuable assets (tacit knowledge) to enhance the worth of the organization. 
Sharing of knowledge is a vital component of the transfer of tacit knowledge. The three aspects of knowledge sharing are relational, cognitive, and structural [44]. The identified dimensions [44], are to be fostered by leaders to facilitate the sharing of tacit knowledge. In the first dimension, relational, the focus is on building trust, respect, and friendship among employees. In the second dimension, cognitive, the attention is on effective communication for creating systems of shared meaning within the organization. The third and the last aspect, structural, centers on building network ties that supported the interactions among employees. All the three elements point to the relevance of commitment in knowledge transfer that Nonaka (1994) identified the main issues in the creation of new knowledge. The three factors that could encourage individual commitment are intention, autonomy, and fluctuation [33].

The intention is the awareness of the individual in creating new knowledge and recognizing the value in them. Autonomy focuses on understanding individual differences and the practice of openness within the organization to optimize the different viewpoints in achieving set goals. The third factor, fluctuation, recognizes the existence of some discontinuity or change in patterns within the organization. However, since the transfer of knowledge is through the interaction between people [33], the effect of fluctuation creates new interactions between individuals, and in turn, create new knowledge.

\section{2: Leadership Role in Knowledge Transfer}

Leadership is the ability to inspire followers through vision and mission [52]. Leadership covers necessary tasks and functions that are required for businesses to succeed, develop, and be efficient [13]. Therefore, leadership functions are into two categories-normal operations and transformation [13]. To be successful in KM, it requires a conscious approach throughout the organization [12:7]. There exists a relationship between life-changing leadership and the productivity of an organization [3]. A transformational leader is instrumental in improving the position of organizations [3]. Leaders' behavior might increase employees' innovative thinking and performance, and that transformational leaders empower employees to be creative and innovative $[3 ; 11]$.

\section{3: Leadership Styles Applicable in Knowledge Transfer}

A leadership style is a method that a leader uses to provide direction, implement plans, and motivate people [52]. Leadership in regular operation offers support and structure by establishing an environment for employees to thrive [52]. In management, there had been an extensive 
discussion on the following leadership styles: transformational, transactional, authoritarian, paternalistic, democratic, and laissez-faire.

2.3.1: Transformational. The principal goal is to transform the followers and redirect their thinking. Leaders with this style, inspire their followers with a sense of purpose [52]. Transformational leaders create a vision and communicate them to their followers [3:11]. Charismatic leaders are knowledgeable and use different strategies to stimulate their followers to think independently [53]. The three stages in the transformational leadership style are communication of importance of assignment, ensuring the realization of organization' objective, and provision of necessary supports to employees.

2.3.2: Transactional. Transactional leaders motivate followers through rewards and punishments. Leaders provide rewards for effort and excellent performance. If subordinates do not meet expectations, leaders maintain the status quo through management by exception and implementation of corrective actions for performance improvement. The focus of transactional leaders is to increase the efficiency of a system by following the established rules. A transactional leader provides and standardizes practices in achieving organizational goals. A transactional leader is either negatively or positively affected, depending on whether the emotional level is high or low, respectively. The leadership style is task oriented [8] and based on a working relationship between leader and employee. Employees can perform their roles and do their best if they understand expectations.

2.3.3: Authoritarian. The authoritative leadership style emphasizes the distinction between leaders and their followers. Direct supervision is the strategy for maintaining a thriving environment, and authoritarian leaders follow the vision of those in control. Authoritarian traits include setting individual goals, engaging one-way and downward communication, controlling, and interaction domination.

2.3.4: Paternalistic. A paternalistic leader acts as a parental figure. The leader has comprehensive care for his/her subordinates and, in return, enjoys the loyalty of his followers. Employees are committed to the leader's beliefs' and are independent. The relationship between leaders and followers is substantial such that workers have more extended employment history because of the trust in leadership that makes workers open to the leaders with any issue. One of the downsides to a paternalistic leadership is an unfair preference. The effect of favoritism may 
erase the benefit of longevity with the organization. The followers of paternalistic leaders have better organizational skills than followers of a transactional leader [35]. Having this style of leadership promoted a reward system that enhanced more accomplishment and boosted employees' self-confidence.

2.3.5: Democratic. In a democratic leadership style, the leader shares the decision-making abilities of followers by practicing social equality, the democratic style beliefs in everyone playing a part in decision making. In research on participative management, the democratic style is one of the most effective and may result in higher productivity, and increased morale [16]. The downside to the democratic leadership is that it works best for followers that are skilled and eager to share knowledge. It requires plenty of time to establish the best course of action.

2.3.6: Laissez-faire. The laissez-faire leadership style gives the power to make decisions wholly to workers and enables followers' self-rule. In the laissez-faire leadership style, leaders provide followers with every support but only involve in decision making unless requested by followers. Laissez-faire leadership is sufficient to use when: (a) employees are highly skilled and experienced, (b) employees take pride in their assignments, (c) employees are outside experts, and (d) followers are trustworthy and experienced.

\section{4: Tacit Knowledge and Leadership Success}

Continuing exploration of tacit knowledge might enhance the success of leaders [43]. However, the personal characteristics of leaders are key factors in the implementation of KM. Such personal traits are social, emotional intelligence, and critical thinking skills. In favor of the above argument, for a leader to be successful, they must possess the following three qualities [46]:

1. Understanding - what to change.

2. The ability to move from old and new personal behavior

\section{Communication skills}

Since an increase in the accumulation and application of tacit knowledge enhances an individual's knowledge grows, the effective transfer of tacit knowledge may support both employees' and leaders' performances [18]. 


\section{0: MATERIALS AND METHODS}

\subsection{Research Setting}

To recruit participants for this study, the authors sent a request to the authorization officers in two organizations; these officers later responded by sending the contact information of potential participants who met the inclusion criteria. The criteria were leaders with a minimum of 10 years of experience at oil and gas company. The firm also had to have a minimum of 20 years of operation in Nigeria and a minimum of 100 employees. Invitation e-mails were sent to 25 individuals on the list. Some potential participants declined to be a part of the study based on their busy schedules; others did not respond to the e-mail. The authors sent consent forms and interview protocols to the participants who responded and set up interviews.

Interviewed 15 participants with 9 participants from one organization and six from the second organization; the distribution was based on the availability of participants. The two organizations have footprints across the Niger Delta region of Nigeria. A case study is a methodological approach that involves the in-depth exploration of a specific bounded system [31]. In this study, the bounded system was the process of transferring tacit knowledge among employees in oil and gas organization. In this study, we conducted semi-structured interviews, transcribed the interviews, and extracted codes and categories. The themes are the conceptual elements that span the categories generated from the transcript. The multiple data sources were used to corroborate and augment evidence from the interviews.

Based on the analyses of the interviews there was no new insight or codes after the 11th interview. Saturation occurs when continued data collection produces no new information or insights into the phenomenon of study. We concluded the existence of data saturation; hence, the study was limited to two cases. The interviewing process and peer checking occurred in the two organizations and spanned 7 weeks. We performed the interviews at the office premises of the participants by administering the script and the informed consent agreement to the research participants. We explained the primary focus of the study before the interview to all participants. The interviews lasted approximately 20-30 minutes. We sent the transcripts to the participants about 2 days after their interview to ensure immediate review for the strength, validity, and reliability of the study. All 15 participants reviewed the transcripts with either minor or no comments. The strength of the study reflects a mixture of interviewees' expertise. The professional knowledge shared by the participants during the face-to-face interviews showed the depth of their knowledge of the phenomenon of interest. 


\section{0: $\quad$ RESULTS AND DISCUSSION}

The central research question of the study was how leaders in the oil and gas industries facilitate the transfer of tacit knowledge among employees. In the following sections, we will present the findings of this study about how leaders in the oil and gas industries in Nigeria facilitate the transfer of tacit knowledge among employees. The selected two organizations have footprints across Nigeria. We purposively selected 15 participants in alignment with the research method and methodology of this research study.

\section{1: Major Themes}

We reviewed semi-structured open-ended questions, notes, and documents by uploading all the sources of data into NVivo 12. The emergent themes resulted from the analysis and interpretation of the data collected from the semi-structured interview question.

\section{Table1}

Emergent Major Themes and Categories from Interviews, Field Notes, and Document Review

\begin{tabular}{lll}
\hline Major themes & \% Occurrence & Categories \\
\hline Safe work environment & 60 & $\begin{array}{l}\text { Diversity, listening, and } \\
\text { culture/behavior }\end{array}$ \\
Caring for the Employee & 40 & $\begin{array}{l}\text { Engagement, encouragement, } \\
\text { and benefit }\end{array}$
\end{tabular}




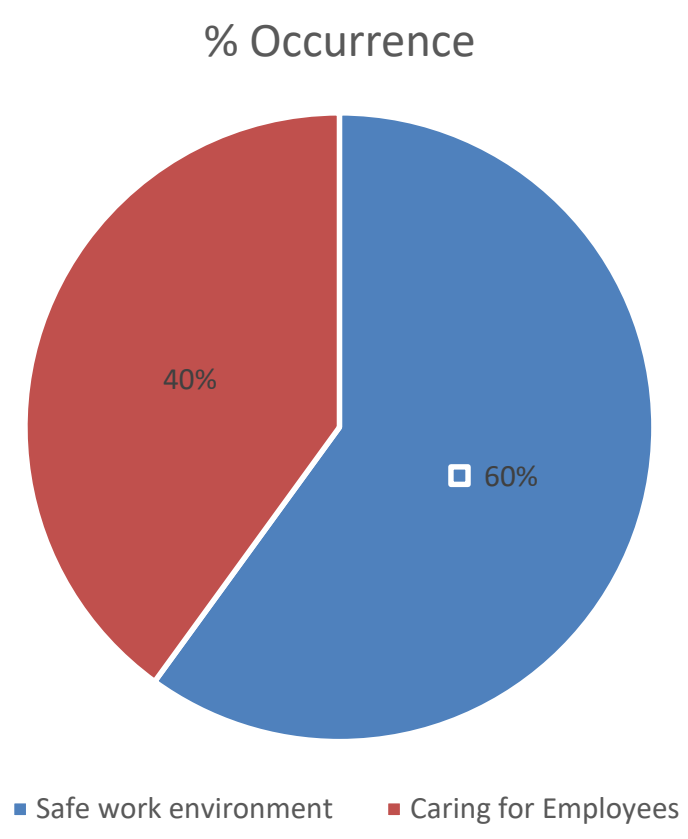

Table2

Inductively Developed Thematic Theme: Safe work Environment

\begin{tabular}{lcc}
\hline Category Code $\quad$ Source & $\%$ Relative \\
& Occurrence
\end{tabular}

\begin{tabular}{lll}
\hline Diversity & Work Rotation & Organization structure chart, newsletter, 34 \\
& weekly update bulletin, project planning \\
& worksheet, field notes, website, interview \\
Listening $\quad$ Feedback & Interview, newsletter, weekly update 33 \\
& bulletin, real-timefeedback sample, website, \\
& QAQC, lesson learned form, website, field \\
& notes \\
& & \\
Culture & Attitude/Behavior & \\
& &
\end{tabular}




\section{Safe Environment}

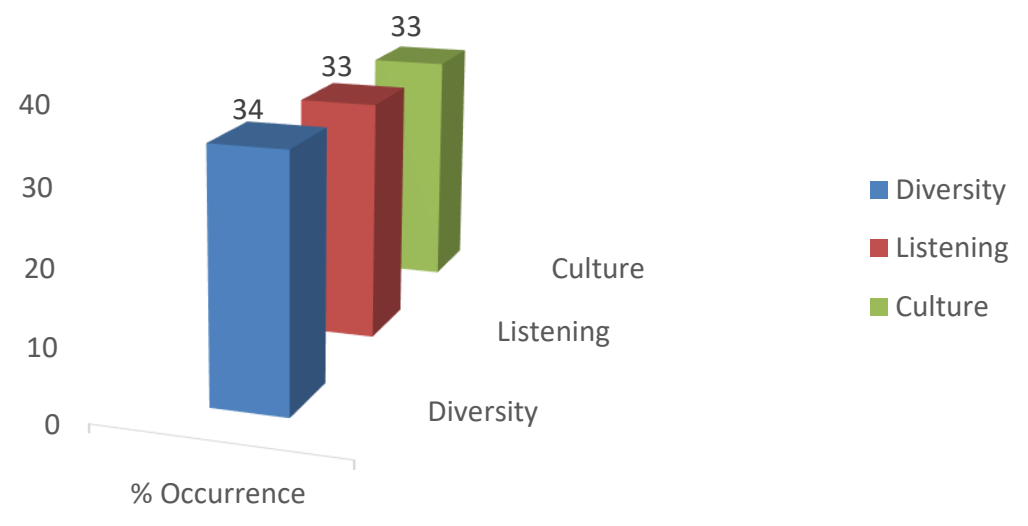

Table

Inductively Developed Thematic Theme - Caring for the Employee

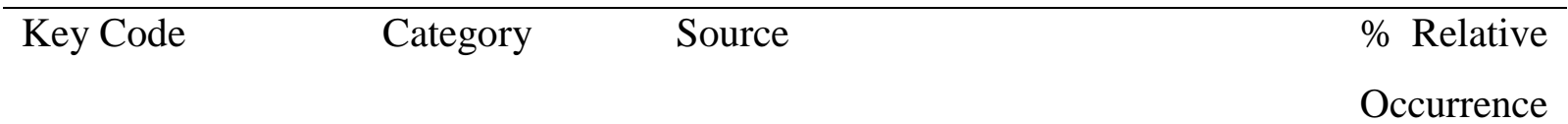

Involvement Engagement

Quarterly Meetings Bulletin, Practice 35

Group Bulletin, Project Planning Form,

Interview, Newsletter, Website, Lesson

Learned

Empathy

Encouragement

Quarterly Meeting Bulletin, Lesson 35

Learned, Interview, Newsletter,

Website, and Field notes

Gain/Appreciation Benefit

Interview, Newsletter, Website, and 30

sheet, Field notes 


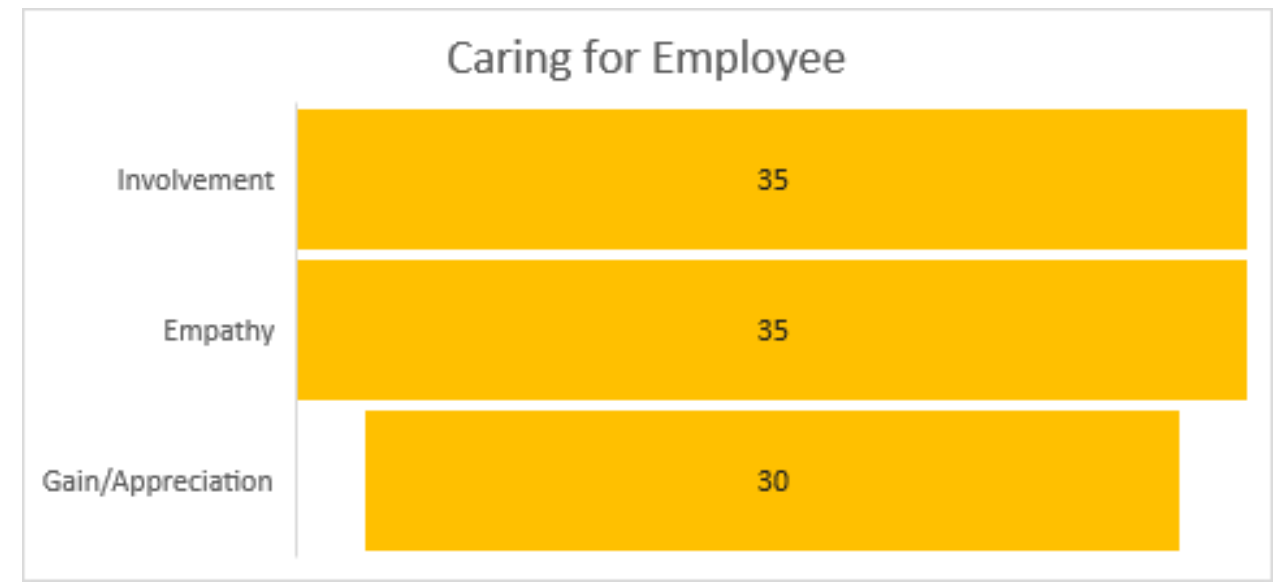

\section{2: Discussion of Findings}

To reach conclusions about the contribution of this study to the existing body of knowledge, we performed a data source analysis with the literature using the conceptual framework to determine the boundaries of the review. The study findings served as the main themes for the review. We discussed the contributions of this study in terms of understanding how leaders are supporting the transfer of tacit knowledge among employees. The research question that guided this study was: How do leaders in the oil and gas industries in Nigeria facilitate the transfer of tacit knowledge among employees? To address the research question, we manually coded the data from the transcribed interviews of the research participants from the two organizations to generate the themes. Two major themes emerged, and we aligned the themes with the findings from the literature review to ascertain the concurrence and to corroborate with the previous research framework.

\subsection{1: Safe working Environment}

From this study, we found that leaders facilitate the transfer of tacit knowledge through the creation of a safe environment for employees. This finding is supported by Garrick and Chan's (2017) that leaders are the facilitators of enabling environment that fosters employees' motivation and safety. It can be inferred that knowledge sharing, through collaboration, thrives in a safe work environment both culturally and behaviorally [32:4].

\subsection{2: Caring for the Employees}

A caring attitude promotes relationships, trust, and communication. Under the umbrella of caring, the findings from this study covered leaders influence on engagement, encouragement, 
and the benefits in sharing knowledge. From this study, we established that leader's engagement with employees tremendously help in facilitating the transfer of tacit knowledge among employees. In addition, every encouragement by leaders brings strength to employees in effort to share tacit knowledge. Furthermore, creating opportunity to celebrate employees facilitate the transfer of tacit knowledge. The findings in this study aligned with Alegre, Sengupta, and Lapiedra (2013), and Iyamah and Ohiorenoya (2015), that knowledge sharing influences performance. Furthermore, negative feelings on how caring leaders are may dampen the sharing of knowledge and loss of such knowledge [23]. In support of the argument of Iyamah and Ohiorenoya (2015), Nonaka (1994) explained that employees will not share tacit knowledge if there is no reward for sharing the knowledge. The development of new knowledge could only be through interactions among employees while organization determines the extent of the interaction [33].

\section{0: CONCLUSION AND RECOMMENDATIONS}

Tacit knowledge transfer has been a topical issue in industrial and educational institutions. From this study, we recognized the knowledge gap created is due to the labor scarcity created by the exit of experienced personnel. Findings indicated that leaders facilitated the transfer of tacit knowledge through the creation of a safe working environment and demonstration of care for the employees. The opportunity to facilitate the transfer of tacit knowledge from expert to employees managing operations after exploration enhance the stability of organizations and the communities they serve.

\section{1: Recommendations}

The projected number of aging or experienced workers exiting the oil and gas industry in Nigeria between 2015 and 2025 will create a labor scarcity that will affect the manpower need of the industry [42]. History has shown that no organization can thrive without formidable human resources. Therefore, it is imperative for leaders in oil and gas industries to embrace the findings in this study to promote knowledge transfer. Leaders must develop deliberate actions to promote safe environment through engagement of all employees. Leaders must encourage employees to express themselves without any fear of repression. Okafor (2019) stated that effective organizational communication is essential and is a major contributor in increasing stakeholders' commitment to operation success. However, ineffective communication reduces certainty and trust that impacts organization negatively [36]. Leaders must develop an action plan on engagement with a measurable metrics to ensure clarity of purpose among participants. It is also 
recommended to develop conscious plans to appreciate employees. The implementation may vary across departments, but leaders can engage employees on how the methodology to ensure the effectiveness of the process.

\section{0: REFERENCES}

Agee, J. (2009). Developing qualitative research questions: A reflective process. International Journal of Qualitative Studies in Education, 22(4), 431-447. doi:10.1080/09518390902736512

Alegre, J., Sengupta, K., \& Lapiedra, R. (2013). Knowledge management and innovation performance in a high-tech SMEs industry. International Small Business Journal, 31(4), 454-470. doi:10.1177/0266242611417472

Amin, W., Akram, U., Shahzad, F., \& Amir, M. (2018). Impact of transformation leadership on affective employee's commitment. European Online Journal of Natural and Social Sciences: Proceedings, 7(1(s)), 48. Retrieved from http://european-science.com

Badara, A. M., Johari, H. B., \& Yean, T. F. (2015). Individual performance, leadership succession, organizational climate and the moderating effect of trust: Data screening and preliminary analysis. Mediterranean Journal of Social Sciences, 6(2), 13. doi:10.5901/mjss.2015.v6n2p13

Bendassolli, P. F. (2013). Theory building in qualitative research: Reconsidering the problem of induction. Forum Qualitative Sozialforschung/Forum: Qualitative Social Research, 14(1). doi:10.17169/fqs-14.1.1851

Beehr, T. A., \& Bennett, M. M. (2015). Working after retirement: Features of bridge employment and research directions. Work, Aging and Retirement, 1(1), 112-128. doi:10.1093/workar/wau007

Braedley, S. (2016). Research on fire: Lessons learned in knowledge mobilization. Technology Innovation Management Review, 6(9), 53-58. doi:10.22215/timreview1020

Budak, F. (2017). The importance of clinical leadership in healthcare management. Journal of Current Researches on Health Sector, 7(2), 1-20. doi:10.26579/jocrehes_7.2.1

Burns, J. M. (1978). Leadership. Harper and Row.

Bussewitz,C., (2020). COVID-19: Oil prices, jobs slashed as global coronavirus spread continues. The Associated Press. Retrieved from 
https://globalnews.ca/news/6613159/oil-prices-china-coronavirus-covid/ Chaudhry, S., \& Joshi, C. (2017). Transformational leadership, HR practices and affective commitment to change: A theoretical perspective. Journal of Organization and Human Behavior, 6(3), 37-45.doi:10.1108/JOHB-05-2016-0506

Dalkir, K. (2013). Knowledge management in theory and practice. Elsevier Butterworth-Heinemann. doi:10.4324/9780080547367

Davis, F. A. (2017). Continuous improvement by improving continuously (CIBIC): Addressing the human factors during the pursuit of process excellence. Productivity Press.

Denner, L., \& Blackman, T. (2013). Knowledge management in the public sector: an online presence as a tool for capture and sharing. Studies and Perspectives Series $\begin{array}{llll}\text { (The } \quad \text { Caribbean), } & \text { Retrieved }\end{array}$ https://www.cepal.org/en/publications/type/studies-and-perspectives-eclacsubregional-headquarters-caribbean

Ding, Z., Zuo, J., Wang, J., \&Zillante, G. (2016). Searching for niche market for engineering consultants. Case of regional supervisor system in China. Engineering Construction \& Architectural Management, 23, 622-637. doi:10.1108/ECAM-092015-0132

Dyczkowska, J., \& Dyczkowski, T. (2018). Democratic or Autocratic leadership style? Participative management and its links to rewarding strategies and job satisfaction in SMEs. Athens Journal of Business \& Economics, 4(2), 193-218. doi:10.30958/ajbe.4.2.5

Dzekashu, W. G., \& McCollum, W. R. (2014). A quality approach to tacit knowledge capture: Effective practice to achieving operational excellence. International Journal of Applied Management and Technology, 13(1), 52-63. doi:10.5590/IJAMT.2014.13.1.04

Garrick, J. (2018). A critical discourse on tacit knowledge management and the performance agenda. Implications for industry training and development. European Journal of Training and Development, 42, 210-225.doi:10.1108/EJTD-12-2017-0107 Garrick, J., \& Chan, A. (2017). Knowledge management and professional experience: The uneasy dynamics between tacit knowledge and performativity in organizations. Journal of Knowledge Management, 21(4), 872-884. doi:10.1108/JKM-02-20170058

Gog, M. (2015). Case study research. International Journal of Sales, Retailing \& 
Marketing, 4(9), 33-41. Retrieved from http://www.ijsrm.com

Gongcheng,Z., Hongjun, Q.,Guojun, C., Chong, Z., Fenglian, Z., Haizhang,Y., Zha, Z., Ming, M. (2019). Giant discoveries of oil and gas fields in global deepwaters in the past 40 years and the prospect of exploration. Journal of Natural Gas Geoscience; (4) 1. https://doi.org/10.1016/j.jnggs.2019.03.002

Imran, M. K., Ilyas, M., \& Aslam, U. (2016). Organizational learning through transformational leadership. The learning organization, 23(4), 232-248. Retrieved from https://www.researchgate.net

Iyamah, F. A., \&Ohiorenoya, J. O. (2015). Knowledge sharing and performance in the Nigerian oil and gas industry. Information and Knowledge Management, 5(3). 8290. Retrieved from academia.edu

Joe, C., Yoong, P., \& Patel, K. (2013). Knowledge loss when older experts leave knowledge-intensive organizations. Journal of Knowledge Management, (6), 913. doi:10.1108/JKM-04-2013-0137

Krylova, K. O., Vera, D., \&Crossan, M. (2016). Knowledge transfer in knowledge intensive organizations. The crucial role of improvisation in transferring and protecting knowledge. Journal of Knowledge Management, 20, 1045-1064. doi:10.1108/JKM-10-2015-0385

Kuciapski, M. (2017). A model of mobile technologies acceptance for knowledge transfer by employees. Journal of Knowledge Management, 5, 1053-1076. doi:10.1108/JKM-03-2016-0136

Lievre, P., \& Tang, J. (2015). SECI and inter-organizational and intercultural knowledge transfer. A case study of controversies around project of co-operation between France and China in the health sector. Journal of knowledge Management, 19, 1069-1086. doi:10.1108/JKM-02-2015-0054

Litchfield, K., Javernick-Will, A., \& Maul, A. (2016). Technical and professional skills of engineers involved and not involved in engineering service. Journal of Engineering Education, 105(1), 70-92. doi:10.1002/jee.20109

Macmillen, J., \& Stead, D. (2014). Learning heuristic or political rhetoric? Sustainable mobility and the functions of 'best practice'. Transport Policy, 35, 7987.doi: 10.1016/j.tranpol.2014.05.017

Millar, C. C., Chen, S., \& Waller, L. (2017). Leadership, knowledge and people in knowledge-intensive organizations: Implications for HRM theory and practice. The International Journal of Human Resource Management, 28(2) 261-275. 
doi:10.1080/09585192.2016.1244919

Mills, A. J., Durepos, G., \&Wiebe, E. (2010). Encyclopedia of case study research (Vols. 1-0). SAGE Publications Limited. doi:10.4135/9781412957397

Neukam, M. N. (2017). Managing the fuzzy front-end in multicultural teams. European Journal and Innovation Management, 20, 578-598. doi:10.1108/EJIM-112016-0112

Northouse, P. G. (2018). Leadership: Theory and practice. Sage

Nonaka, I. (1994). A dynamic theory of organizational knowledge creation. Organization Science, 5(1), 14-37. doi:10.1287/orsc.5.1.14

Nonaka, I., \& Takeuchi, H. (1995). The knowledge-creating company: How Japanese companies create the dynamics of innovation. Oxford University Press.

Okafor, A. (2019). Refocusing on the Success Enabling Factors in Mergers and Acquisitions. European Scientific Journal June. doi:10.19044/esj.2019.v15n16p172 Perjanik, N. S. (2016). Tacit knowledge capture and the brain-drain at electrical $\begin{array}{llll}\text { utilities } & \text { (Doctoral fissertation). } & \text { Retrieved }\end{array}$ https://scholarworks.waldenu.edu/cgi/viewcontent.cgi? article=3524\&context=disser tations

Pereira, C. A. B., Alves, H. M. B., \& Ferreira, J. J. M. (2016). Impact of tacit knowledge on customer loyalty. The Service Industries Journal, 36(15-16), 827-845. doi:10.1080/02642069.2016.1272596

Pérez-Luño, A., Saparito, P., \&Gopalakrishnan, S. (2016). Small and medium-sized enterprise's entrepreneurial versus market orientation and the creation of tacit knowledge. Journal of Small Business Management, 54(1), 262-278. doi:10.1111/jsbm.12144

Qu, R., Janssen, O., \& Shi, K. (2015). Transformational leadership and follower creativity: The mediating role of follower relational identification and the moderating role of leader creativity expectations. The Leadership Quarterly, 26(2), 286-299. doi: 10.1016/j.leaqua.2014.12.004

Ragsdale, J. (2018, May 8). The state of knowledge management: 2017. Technology Services Industry Association, Retrieved from www.tsia.com/resources/the-state-ofknowledge-management-2017

Reder, W., Bose, A., Flueck, A., Lauby, M., Niebur, D., Randazzo, A., \&Wayno, F. (2010). Engineering the future. IEEE Power and Energy Magazine, 8(4), 27-35. doi:10.1109/MPE.2010.937125 
Ren, X., Deng, X., \& Liang, L. (2018). Knowledge transfer between projects within project-based organizations. The project nature perspective. Journal of Knowledge Management, 22, 1082-1103. doi:10.1108/JKM-05-2017-0184

Sandybayev, A., \& Y1lmaz, B. (2015). Charismatic leadership and organizational culture: A Northern Cyprus perspective on the police service employees. International Journal of Research in Management, 5(2). Retrieved from http://www.rspublication.com/

Saxena, A., Davies, M., \& Phillippon, D. (2018). Structure of healthcare dyad leadership. An organization's experience. Leadership in Health Services, 31, 238253. doi:10.1108/LHS-12-2017-0076

Srivastava, P., \& Jain, S. (2017). A leadership framework for distributed selforganized scrum teams. Team performance management. International Journal, 23(5/6), 293-314. doi:10.1108/TPM-06-2016-0033

Swensen, S., Gorringe, G., Caviness, J., \& Peters, D. (2016). Leadership by design. International organization development of physician leaders. Journal of Management Development, 35, 549-570. doi:10.1108/JMD-08-2014-0080

Tsai, Y., Wang, H., \& Yuan, C. (2015). Transformational leadership and job performance: The case of SMEs in Taiwan. International Journal of Arts and $\begin{array}{llll}\text { Commerce, } & 4(8), & 57-71 . & \text { Retrieved from }\end{array}$ https://www.ijac.org.uk/images/frontImages/gallery/Vol._4_No._8/7._57-71.pdf Tse, H. M., Huange, X., \& Lam, W. (2013). Why does transformational leadership matter for employee turnover? A multi-foci social exchange perspective. The Leadership Quarterly, 24(5), 763-776. doi: 10.1016/j.leaqua.2013.07.005

Wang, Z., Zhou, H., \& Ding, Y. (2010). Knowledge sharing and new business development in engineering consulting organizations. In Information Science and Engineering (ICISE), 2010 2nd International Conference on (pp. 310-314). IEEE. doi: 10.1109/ICISE.2010.5691164

Witmer, A. (2018). Contextual engineering assessment using an influence identification tool. Journal of Engineering Design and Technology, 16(6), 889-909. doi:10.1108/JEDT-05-2018-0091

Yazan, B. (2015). Three approaches to case study methods in education: Yin, Merriam, and Stake. The Qualitative Report, 20(2), 134-152. Retrieved from https://nsuworks.nova.edu/tqr/vol20/iss2/12

Yıldız, S., Baştürk, F., \&Boz, İ. T. (2014). The effect of leadership and 
innovativeness on business performance. Procedia - Social and Behavioral Sciences, 150, 785-793. doi: 10.1016/j.sbspro.2014.09.064

Zhou, L., Zhao, S., Tian, F., Zhang, X., \& Chen, S. (2018). Visionary leadership and employee creativity in China. International Journal of Manpower, 39(1), 93-105. doi:10.1108/ijm-04-2016-0092 